gramme of reduction begun by his predecessor Thomas Henderson, and maintaining expert meteorological records, Smyth engineered challenging initiatives in physical astronomy. His achievements with the spectroscopes he bought in London and Paris or designed and adapted himself are detailed in the book. Smyth identified telluric absorption, mapped the rainband to improve weather forecasts, introduced vacuum tubes to analyse gas spectra, and investigated zodiacal and auroral light. With the physicist Alexander Herschel, John's son, Smyth established a harmonic series in the $\mathrm{CO}$ green band; with the Edinburgh natural philosopher Peter Guthrie Tait he proposed spectroscopic trials to detect the Earth's motion through the ether.

These programmes would have been enough to make a leader in astrophysics, but Smyth's ambitions were much wider. His research can only be understood in the context of changes in Victorian astronomy. The mid-nineteenth century witnessed a shift in disciplinary organization as the great observatories, such as Airy's at Greenwich or Struve's at Pulkovo, became centres of regimented enquiry. Airy, with whom Smyth found it increasingly difficult to maintain cordial relations, turned Greenwich into a factory-like regime, subordinating observers to the rank of menials and constructing a system of vigilant management. Smyth criticized this strategy. He denied that Adams and Leverrier, the joint 'discoverers' of Neptune, should be labelled 'astronomers', because they were not observers of the heavens but merely mathematicians. Theorists luxuriated while proper observers suffered for their vocation. His Edinburgh courses in practical astronomy were unsuccessful, and he rejected the popularization espoused by his opposite number at Glasgow, J. P. Nichol. His hopes for "communion between workers in metal and workers in paper" were frustrated. His campaign for the establishment of mountain-top observatories, initiated with a trip to Teneriffe in 1856 , gained some support and won him a Fellowship of the Royal Society, but it did not easily change astronomers' interests in the established metropolitan observatories.

All this made Smyth a respected but troubling gadfly on the body of his profession. More eccentric was his lengthy campaign in metrology and the interpretation of the Great Pyramid of Gizeh. Trips to Egypt and contacts with other pyramidologists convinced Smyth that the Pyramid embodied pristine mathematical truths divinely revealed to its builders. Smyth cited John Herschel's authority in his support. He fought James Clerk Maxwell over the meaning of the sacred cubit, a controversy which led to his resignation from the Royal Society. The authors of this biography find such claims slightly embarrassing, rightly stressing the solid skills in precision measurement Smyth displayed but excusing his enthusiasm for scriptural metrology and Egyptian mysticism.

Yet Smyth's pyramidology is perhaps less inexplicable than it appears. Smyth used the relation between the sacred cubit and the inch to bolster his fight against metrication and his views on standards; any ally in the fight against French republican or Prussian reformist measures was warmly welcomed. Moderate theological views about precision standards were not uncommon - Maxwell himself expressed such opinions in the 1870 s. But Smyth's profound political conservatism and scriptural fundamentalism uniquely combined commitment to practice over theory with a belief that the Pyramid showed the millennium would arrive in

\section{On to experiment}

\section{Stig Stenholm}

Laser Light Pressure on Atoms. By V.G. Minogin and V.S. Letokhov. Gordon \& Breach:1987. Pp.248. \$75, £40.

LASER spectroscopy has long been concerned with the exchange of energy between electromagnetic radiation and the internal levels of atoms. When the accompanying exchange of momentum is taken into account, the theory comes into the province of the physics of laser light pressure.

Minogin and Letokhov's book is the first to present a unified and pedagogical account of this subject. It starts with a brief historical introduction, after which the text is divided into two parts. The first is a systematic and thorough account of the calculation of mechanical effects of light, the material being presented in sufficient depth to make it appropriate as the basis for a lecture course or for self-study.

The second part contains a more detailed description of the mathematical methods used in the discussion of laser cooling. The treatment is systematic and comprehensive in its coverage. It is based on an adiabatic elimination of the fast internal degrees of freedom of the atom and leads to a description of its motion in the configuration space of its centre of mass. Here the reader is expected to work a bit harder to grasp the details. The authors concentrate on the theoretical methods they have used in their own work and the theory is illustrated by experimental results. Cohen-Tannoudji's dressed-atom approach and the alternative theories worked out by Kazantsev are not discussed.

Brief accounts only are devoted to
1882. He agonized about the regimentation of his science. His travels convinced him that astronomers must change their ways, and that the ancient craftsmen to whom God had spoken provided the best model for Victorian observers. It was appropriate that the first response to his proposal for mountain observatories was developed in an 1859 Russian expedition to Mount Ararat. Only an anachronistic judgement of Victorian values prevents the recognition that the Great Pyramid could provide an excellent case for evangelical astronomy. The Peripatetic Astronomer provides a valuable opportunity to explore the moment at which such ancient and modern forms of worship and of science could co-exist.

Simon Schaffer is Lecturer in the Department of History and Philosophy of Science, University of Cambridge, Free School Lane, Cambridge CB2 3RH, UK.

radiation-induced diffraction in the coherent case (when relaxation is neglected) and the cooling of trapped particles, while the quantum (Lamb-Dicke) limit of traps is not covered. The text ends with a concise survey of applications, after which comes a list of 202 references. These are numbered in the order in which they appear in the text, an unfortunate practice which makes an overview difficult, and there are a few errors. But on the whole this is a representative and useful compilation, which laudably extends into 1986.

The authors have translated and revised the English edition themselves. The resulting prose generally reads very well, but there are a few annoying slips that should have been corrected in the editorial process.

The theory of laser light pressure is now well advanced and the experimental effort is growing rapidly, so the publication of Minogin's and Letokhov's volume is timely. The book will be of value for some time to come, and anyone wishing to get some insight into this subject will benefit from reading it.

Stig Stenholm is Director of the Research Institute for Theoretical Physics, University of Helsinki, Siltavuorenpenger 20C, 00170 Helsinki, Finland.

\section{New in paperback}

- The Anthropic Cosmological Principle by John D. Barrow and Frank J. Tipler. Publisher is Oxford University Press, price is £9.95. For review see Nature 320, 315 (1986).

- In the Company of Animals: A Study of Human-Animal Relationships by James Serpell. Publisher is Basil Blackwell, price is $£ 7.95, \$ 19.95$. For review see Nature 323, 210 (1986)

- The Other World: Spiritualism and Psychical Research in England, 1850-1914 by Janet Oppenheim. Publisher is Cambridge University Press, price is $£ 12.95, \$ 14.95$. For review see Nature 316, 25 (1985). 